\title{
ИЗМЕНЕНИЯ В ВЕДЕНИИ КАССОВЫХ ОПЕРАЦИЙ В 2018-2019 ГГ.
}

\author{
Е. А. Двойнева \\ Московский гуманитарный университет
}

\begin{abstract}
Аннотация: В статье рассмотрена обязанность по соблюдению кассового порядка, который распространяется на все организации и деятельность индивидуальных предпринимателей в Рос-

Текст доклада автора на Общероссийской (национальной) научной конференции «Моисеевские чтения. Культура и гуманитарные проблемы современной цивилизации», которая состоялась 4-5 марта 2020 2. в Московском гуманитарном университете.
\end{abstract} сии.

Ключевые слова: касса; кассовая операция; ЦБ РФ; ККТ

\section{CHANGES IN CASH TRANSACTIONS IN 2018-2019}

\author{
E. A. Dvoyneva \\ Moscow University for the Humanities
}

Abstract: The article discusses cash register compliance obligations that apply to all organizations and individual entrepreneurs in Russia.

The text of the author's speech at the All-Russian (National) Scientific Conference "Moiseev's Readings. The Culture and Humanitarian Issues of Modern Civilisation", which was held at Moscow University for the Humanities on 4-5 March, 2020.

Key words: cash register; cash transaction; CBRF; POS

Федеральный закон от 06.06.2019 № 129-ФЗ «0 внесении изменений в Федеральный закон “О применении контрольно-кассовой техники при осуществлении расчетов в Российской Федерации"» - значимый для многих организаций и индивидуальных предпринимателей, так как именно он дает им право еще целых два года вести свою деятельность без применения контрольно-кассовой техники. Относится это к налогоплательщикам, которые производят свои собственные товары, лично выполняют работы, оказывают услуги без привлечения наемного персонала.

Процедура использования кассовых аппаратов для дистанционной торговли и в некоторых других случаях была упрощена. Поговорим об этом более подробно.

Согласно первоначальному плану законодателя, переход на онлайн-кассы должен был состояться оперативно: для крупного и большей части среднего бизнеса, с 1 июля 2017 г. такие кассовые аппараты стали обязательными (пункт 3 статьи 7 Федерального закона от 29.06.16 №290-ФЗ). (Химич, 2017: 13-14). Данные налогоплательщики оказались на первом этапе кассовой реформы.

Шанс получить отсрочку выпал одновременно нескольким категориям организаций и ИП, применять ККТ данные налогоплательщики должны были в ходе второго этапа кассовой реформы. 
1 июля 2018 г. подходил к концу переходный период и все расчеты (за исключением тех, кто в соответствии с законом от 22.05.2003 № 54-Ф3 освобожден от применения ККТ), обязаны были передавать фискальные данные в ФНС в онлайнрежиме. Но как выяснилось, никто не был готов должным образом соблюдать нововведение: ни власть, ни проверяющие органы, ни проверяемые лица, ни сами производители кассовых аппаратов. В связи с чем решили не рисковать.

В конце 2017 г. был принят Федеральный закон от 27.11.17 № 337-Ф3, который продлил переходный период до 1 июля 2019 г., породив тем самым третий этап перехода на новые кассы.

Первоначально третий этап распределял налогоплательщиков на две категории.

К первой относились лица, которые без каких-либо дополнительных условий, могли не регистрировать онлайн-кассу до июля 2019 г.: организации и индивидуальные предприниматели при выполнении работ и оказании услуг населению (за исключением услуг общественного питания); ИП на ЕНВД (организации и индивидуальные предприниматели) по всем видам деятельности, кроме общественного питания и розничной торговли; ИП на патенте осуществляющий вид деятельности не связанный с розничной торговлей.

Ко второй категории относились лица, которым предстояло перейти на онлайн-кассы, и кто мог не применять ККТ до июля 2019 г. только в том случае, если они работали без наемного персонала: предприниматели, торгующие игровыми автоматами, работающие в сфере общественного питания, предприниматели, которые являются плательщиками ЕНВД и ПСН, занимающиеся розничной торговлей.

Но в середине 2018 г. на основании Федерального закона № 192-ФЗ от 03.07.2018 получили отсрочку и попали в третий этап организации и предприниматели при совершении расчетов с физическими лицами, не являющимся индивидуальными предпринимателями, при безналичном способе оплаты (за исключением платежей с использованием электронных средств платежа); при расчетах за жилые помещения или коммунальные услуги, в стоимость которых включены взносы на капитальный ремонт; зачета и возврата предварительной оплаты и (или) авансов; при расчетах по предоставлению займов для оплаты товаров, работ, услуг; при продаже проездных документов (билетов) и талонов в салоне транспортного средства. При этом предпринимателям, применяющим патентный режим налогообложения, при осуществлении некоторых видов деятельности, разрешили ККТ не использовать (Химич, 2017).

ИП, которые ведут свою деятельность самостоятельно, т. е. оказывают услуги или выполняют работы своими силами, вправе не применять онлайн-кассы до 1 июля 2021 г. Также до указанной даты освобождение от применения ККТ имеют ИП без наемных сотрудников, которые продают товар собственного производства, а некоторые налогоплательщики и вовсе получили полное освобождение от применения онлайн-касс при осуществлении безналичных расчетов, в том числе с помощью банковских карт через интернет или онлайн-банки (Логвиненко, 2017).

К ним относятся:

- товарищества собственников недвижимости, жилищные, жилищностроительные кооперативы и другие специализированные потребительские кооперативы. Расчеты за оказание услуг своим членам в рамках уставной дея- 
тельности, а также при приеме оплаты за жилое помещение и коммунальные услуги освобождаются от применения ККТ;

- образовательные и спортивные организации, а также различные дома, дворцы и центры культуры и отдыха, которые предоставляют соответствующие услуги населению.

Если эти услуги оплачиваются наличными или банковскими картами при их предъявлении, т. е. при непосредственном взаимодействии с клиентом (покупателем) придется пробивать кассовый чек.

Индивидуальные предприниматели, реализующие с рук или лотка билеты в театры, являющиеся государственными или муниципальными учреждениями, вправе полностью обойтись без онлайн-касс, данное освобождение действует вне зависимости от формы расчетов с клиентом, но при этом продажа подобного рода билетов (абонементов) через интернет-сайт должны быть пробиты по ККТ.

Введены также упрощения по порядку применения кассовой техники в ряде случаев, например, при продаже проездного билета в транспортном средстве, разрешено не печатать бумажные кассовые чеки, будет вполне достаточно, если водитель (кондуктор) выдаст пассажиру билет, в котором будет указано, каким образом можно будет получить чек в электронной форме, например, может быть указана ссылка на сайт. Но есть очень важный момент: такого рода чек должен быть создан до конца дня, в котором он был реализован.

Рассмотрим еще одно послабление. Касается оно компаний, которые выдают чеки при оплате за жилое помещение, коммунальные услуги и не попадают под описанное выше освобождение, то есть они не являются товариществами, кооперативами и т. д.

Все расчеты (за исключением наличных и банковских карт при их предъявлении) за жилое помещение и коммунальные услуги можно не направлять электронный чек, но при условии, если клиент не потребовал данный чек. Запросить подтверждение платежа (выдачу чека) клиент вправе не позднее трех месяцев с момента формирования чека, а по закону, не позднее пяти рабочих дней со дня поступления денег на счет, чек должен быть сформирован. По истечению трехмесячного срока обязанность по выдаче чека признается исполненной, даже если клиент не требовал предоставления чека.

Закон не делает никаких исключений, если ИП оказал разовую услугу, или время от времени выполняет работы, расчеты по которым должны сопровождаться выдачей чека, то данный предприниматель обязан применять ККТ, так что перед осуществлением какой-либо деятельности, необходимо внимательно изучить все законы и положения о применении ККТ, ведь незнание закона не освобождает от ответственности. Чем быстрее предприниматель начнет применять ККТ, тем будет лучше для его бизнеса.

Рассмотрев основные этапы формирования кассой реформы, можно сделать вывод о преимуществах нововведения. Использование ККТ нового порядка позволяет перевести значительную часть работы в онлайн-режим, предприниматели прекратят вести учет «в тетрадку», что позволит им повысить эффективность своей работы. Из тени будет выведена часть продаж, не зафиксированная продавцами и в бюджет с этих сделок, начнут поступать налоги. 


\section{СПИСОК ЛИТЕРАТУРЫ}

Логвиненко, К. В. (2017) Вопросы ведения онлайн-касс [Электронный ресурс] // Молодой ученый. № 44(178). C. 113. URL: https://moluch.ru/archive/178/46237/ (дата обращения 22.02.2020).

Химич, Н. В. (2017) Онлайн-кассы. Революция в применении кассовой техники. М.: Сервис-ККМ.

Дата поступления: 30.03.2020 г.

Двойнева Елизавета Андреевна - студент факультета экономики, управления и международных связей, направление подготовки «Экономика», профиль «Бухгалтерский учет, анализ и аудит» Московского гуманитарного университета. Адрес: 111395, Россия, г. Москва, ул. Юности, д. 5. Эл. адрес: oira-oira2@mail.ru

Dvoyneva Elizaveta Andreyevna, Student, Faculty of Economics, Management and International Relations, academic program "Economics", specialisation "Accounting, Analysis and Audit", Moscow University for the Humanities. Postal address: 5, Yunosti St., Moscow, Russian Federation, 111395. E-mail: oira-oira2@mail.ru

\section{Для цитирования:}

Двойнева Е. А. Изменения в ведении кассовых операций в 2018-2019 гг. // Научные труды Московского гуманитарного университета. 2020. №2. С. 28-31. DOI: 10.17805/trudy.2020.2.5 